\title{
Information provision and attentive listening as determinants of patient perceptions of shared decision-making around chronic illnesses
}

\author{
Ana-Belén del Río-Lanza ${ }^{1,2^{*}}$ (1) Leticia Suárez-Álvarez ${ }^{1}$, Ana Suárez-Vázquez ${ }^{1}$ and Rodolfo Vázquez-Casielles ${ }^{1}$
}

\begin{abstract}
Background: While chronic illnesses are a major concern of the health system worldwide, little is known about patients-physicians communication. Growing demand for patient-centered care and shared decision-making have increased the interest for patients-physicians communication. Based on previous literature, we propose a model in which the effect of information provision and attentive listening over patients' perceptions of shared decision-making (PPSDM) is mediated by the variables self-efficacy and proactivity. Primary data were collected between April and August 2014 through an online survey of patients with haemophilia. Haemophilia is a chronic disease in which many options of treatment are available. The right option depends, to some extent, on patient's preferences. In this context, great uncertainty exists when choosing treatment option and shared decision-making plays an essential role.
\end{abstract}

Results: A total of 181 patients with haemophilia participated in the survey. The psychometric properties of the measurement scales were evaluated by means of a confirmatory factor analysis. A structural equation model was designed. Results show that provision of information and attentive listening determine PPSDM through patients' selfefficacy and proactivity in requesting information.

Conclusions: It is important to incorporate communication training in medical education, particularly provision of information and attentive listening. These skills help the healthcare professional to gain a deeper understanding of the patient. Furthermore, provision of information and attentive listening are fundamental in helping patients not to undervalue their personal knowledge and expertise in relation to their doctors. These strategies encourage them to adopt a more active position in requesting information. Encouraging a proactive behaviour of patients and their relatives helps them to realize the need to participate and to make them feel that they are part of the decision-making process.

Keywords: Decision making, Patients perspective, Self efficacy, Proactive behaviour, Chronic disease, Patientcentered care, Physician-patient relations, Communication programs

\section{Background}

The World Health Organization (WHO) estimates that by $2020,60 \%$ of all diseases around the world will be chronic illnesses, and they will cause three-quarters

\footnotetext{
*Correspondence: adelrio@uniovi.es

${ }^{1}$ Biomedicine and Health Cluster, Business Administration Department, School of Economy and Business, University of Oviedo, Avenida del Cristo s/n, 33071 Oviedo, Asturias, Spain

Full list of author information is available at the end of the article
}

of the world's deaths. Chronic illnesses are becoming increasingly prevalent (WHO 2011) and leading to rising costs in the economies of the world (McAdam 2013). In this context, a patient-centered health care system seems to be crucial to satisfy the needs of patients with chronic conditions. The goal of this system is threefold (Cramm and Nieboer 2014): (1) to inform the patients to improve the knowledge about their own illness; (2) to activate the patients to increase the roles they assume in the illness 
management; (3) to promote the interaction between patients and healthcare professionals. Shared decisionmaking (SDM) appears as an approach able to cope with this necessity of enhancing the quality of care of chronically ill patients and improving the relationships between patients and healthcare professionals (Branda et al. 2013; Siegel et al. 2015).

SDM describes an interaction process in which both patient and doctor participate actively in finding an agreement based on shared information. The objective is to reach a decision in which both patient and physician are involved (Hölzel et al. 2013). Patient participation in health care is seen as an important ethical, legal and social aspiration (Lam et al. 2014). Thus SDM is now widely regarded as an essential component to reduce the asymmetry in information exchange and power distribution between doctor and patient (Charles et al. 1997) and as a means of providing good quality healthcare (Entwistle and Watt 2006) and improving patient satisfaction and treatment adherence (Joosten et al. 2008).

In general, the literature on SDM suggests that patients with chronic illnesses want to be told about treatment alternatives and to be involved in treatment decisions to encourage them to take a more active role in medical decision-making (Hamann et al. 2007; van den BrinkMuinen et al. 2011). But SDM is difficult to apply in practice (Elwyn et al. 2012; Blair and Légaré 2015) and some patients take on a passive role in the decision-making (Tariman et al. 2010; Petriwskyj et al. 2014). This is due to multiple barriers to do with the patient, the healthcare professionals and the institutional framework (Légaré et al. 2006; Frosch and Elwyn 2014; Joseph-Williams et al. 2014). Thus recent work calls for research into the antecedents of SDM (Joseph-Williams et al. 2014; Shay and Lafata 2015). According to Kriston et al. (2010, p. 94) "in contrast to its outcomes, the process of SDM is rather under researched and has not received much attention in the past".

It is important to analyze patients' perceptions of SDM (henceforth, PPSDM). Previous research shows that the patient's perspective of SDM differs from the doctor's perceptions (Janz et al. 2004; Fiks et al. 2011) and from observer ratings (Burton et al. 2010; Wunderlich et al. 2010). Moreover, in a recent systematic review of SDM, Shay and Lafata (2015) find that when studying the relation between SDM and patient outcomes (such as improved satisfaction and less decisional conflict), the measurement perspective that most often shows a significant, positive relation with patient outcomes is patient self-reports.

With this in mind, our objective with this work is to model the impact of provision of information and attentive listening on PPSDM. We test five hypotheses via structural equation modelling (SEM). This statistical technique is a modelling approach that can be used to simultaneously model the pathways of influence of multiple variables on outcomes of interest.

\section{Research model and hypotheses}

The complexity of patients-physicians communication have led to analyze it from different points of view. At least three dimensions can be considered when approaching it (Tates and Meeuwesen 2001).

\section{Relational dimension}

It allows to distinguish between instrumental or task focused-behaviour, oriented to the cure, and affective or socio-emotional behaviour, oriented to the care. While asking questions and providing information are essential in a task focused-behaviour, empathy and the ability to show concern are relevant skills in socio-emotional behaviour.

\section{Structural dimension}

It describes unequal positions between the doctor and the patient in terms of power, autonomy and responsibility in decision making.

\section{Linguistic dimension}

A dimension related with the content of the interaction. It alludes to the linguistic dimension in medical encounters. It reflects how, due to differences in previous knowledge, different patients can assign different meanings to the same terms.

This paper focuses on the first dimension mentioned, the relational one. Taking into account previous literature, four variables and its effect over PPSDM have been considered: health care professionals' information provision (PI); health care professionals' attentive listening $(\mathrm{AL})$; patient' self-efficacy (SE) and patient' proactive behaviour (PB).

Following Liang et al. (2002) and Maly et al. (2004) we assume that providing practical advice and correct information that is personalized according to the patient's individual circumstances is associated with a greater perception of choice and more involvement in the decision-making. What is less researched is how healthcare professionals' provision of information can influence PPSDM. Oftedal et al. (2010) argue for the need to give higher priority to practical advice and information as a means of stimulating the patient's self-efficacy-i.e. their expectations of being able to cope with their illness by increasing knowledge, reducing feelings of uncertainty, and enhancing emotional and social adjustment (Carpenter et al. 2010). The first hypothesis of this work is as follows: 
Hypothesis 1 (H1): Healthcare professionals' provision of information has a positive effect on patient self-efficacy.

Hartman et al. (2013) show that it is important to listen to the patient and to listen actively, for example summarizing the patient's beliefs and concerns. Attentive listening is seen as a comprehensive way of dealing with patient orientation because it makes people feel respected, important, intelligent, confident, liked and valuable and creates a trusting atmosphere. For all this, attentive listening environments have been assumed to promote a free and open exchange of ideas and information (King 1978) and improve the doctor-patient relationship (Jagosh et al. 2011). Likewise, Hausman (2004) finds that when the doctor has a personal and close relationship with the patient, and listens to their requirements, a two-way communication ensues from doctor to patient and from patient to doctor. As a consequence, we propose that:

Hypothesis 2 (H2): Healthcare professionals' attentive listening has a positive effect on patient proactivity in requesting information.

The increasing importance of the relational dimension of patients-physicians communication reflects a change from physician-centered care towards patient-centered care. A different concept of patients characterized by higher levels of self-organization and proactivity, underlies this movement. This model implies a change from an approach based on doctors' power and autonomy to an approach based on patients' power and autonomy. In this context, patients have to feel a relationship between actions and results (Bandura 1998). Self-efficacy seems to be a crucial factor to increase patients' proactivity by encouraging them to pose questions, to discuss their preferences and to disagree with recommendations (Kahana and Kahana 2003; Mallin et al. 2014). So the claim could be made that:

Hypothesis 3 (H3): Patient self-efficacy has a positive effect on patient proactivity in requesting information.

In parallel, Heckman et al. (2011) argue that self-efficacy is associated with increased participation in treatment decision-making and improved health-related quality of life. Hypothesis 4 tests this relation in the context of this work:

Hypothesis 4 (H4): Patient self-efficacy has a positive effect on PPSDM.
Finally, assuming that an individual's proactive behaviour refers to anticipatory, change-oriented and selfinitiated behaviour in different situations, Kahana and Kahana (2003) argue that patients' proactivity in communicating with their doctors is likely to receive encouragement for expressing their screening preferences. Additionally, patient proactivity in communication involves assertiveness in acting as healthcare consumers and in seeking to take an active role in medical decisionmaking (Kahana and Kahana 2001). The final hypothesis of this work follows:

Hypothesis 5 (H5): Patient proactivity in requesting information has a positive effect on PPSDM.

Based on these previous comments (see Table 1) we propose the model shown in Fig. 1.

\section{Methods}

\section{Study population}

Haemophilia is a chronic, congenital illness characterized by a deficiency in a clotting factor-a protein in the blood that controls bleeding. As a result, people with haemophilia can bleed for longer than normal, and some may experience bleeding into joints, muscles, or other parts of their bodies that can lead to joint damage and disability. This disorder, especially in its severe forms, has been associated with mortality and morbidity (Salem and Eshghi 2013). Prophylactic therapy, which involves regular factor replacement (at least three times per week or daily), is of critical importance (Manco-Johnson et al. 2007). Haemophilia is a chronic disease characterized by the existence of more than one possible treatment option.

\section{Table 1 Hypotheses and theoretical basis}

\begin{tabular}{ll}
\hline Hypotheses & References \\
\hline $\begin{array}{l}\text { H1: Healthcare professionals' provision } \\
\text { of information has a positive effect }\end{array}$ & Liang et al. (2002) \\
on patient self-efficacy & Maly et al. (2004) \\
& Carpenter et al. (2010) \\
& Oftedal et al. (2010) \\
H2: Healthcare professionals'attentive & King (1978) \\
$\begin{array}{l}\text { listening has a positive effect on } \\
\text { patient proactivity in requesting }\end{array}$ & Hartman et al. (2013) \\
information & Jagosh et al. (2011) \\
$\begin{array}{cl}\text { H3: Patient self-efficacy has a positive } \\
\text { effect on patient proactivity in }\end{array}$ & Kahana and Kahana (2003) \\
requesting information & Mallin et al. (2014) \\
H4: Patient self-efficacy has a positive & Heckman et al. (2011) \\
effect on PPSDM & \\
H5: Patient proactivity in requesting & Kahana and Kahana (2001, 2003) \\
information has a positive effect on & \\
PPSDM &
\end{tabular}




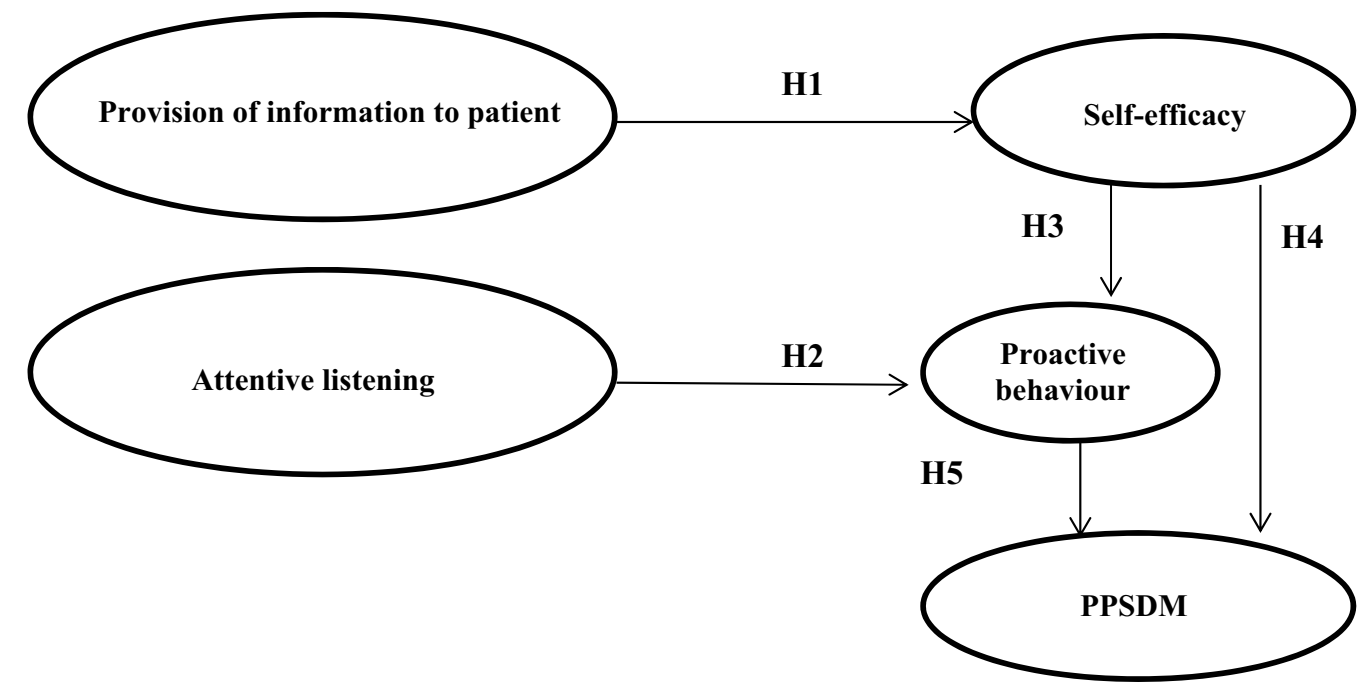

Fig. 1 Research model and hypotheses

Actually, there are no evidence-based indications to identify the better treatment option (Athale et al. 2014). In this context, great uncertainty exists when choosing the right treatment option and SDM plays an essential role. For this reason, it is fundamental that healthcare providers encourage patients to develop an understanding of their condition and to participate actively in the decisionmaking, reporting their bleeding symptoms and physical status.

\section{Data collection and sample size}

We collected data from haemophilia patients resident in Spain. The patients had the two types of haemophilia: haemophilia A or B (in haemophilia A patients do not have enough factor VIII, in haemophilia B they do not have enough factor IX). Participants in the study had to be 18 years or older. In the case of minors, we collected the information from the parent who had the most contact with the healthcare professionals.

In general, subjects were recruited through the Spanish Federation of Haemophilia and regional haemophilia organisations, which mainly by e-mail, telephone and webpage encouraged their members to participate in the study. We obtained some other participants through the Spanish Society of Haemostasis and Thrombosis, which informed haematologists through its webpage. The first participants were recruited in the XLIII National Assembly and XXI Medical-Social Symposium of the Spanish Federation of Haemophilia. The data collection lasted 4 months (from April to August 2014). Employing a convenience sampling approach we obtained a total of 181 participants, of whom $53 \%$ are patients and the rest parents answering for their underage children affected by haemophilia. Haemophilia affects only males, so the patient sample consists of males with a mean age of 27 $(\mathrm{SD}= \pm 17.9)$. The majority of the patients $(61 \%)$ receive their pharmacological treatment very frequently (every week), $13 \%$ less frequently (once, twice or three times a month) and $26 \%$ infrequently (every five or more weeks).

We collected the data using an online survey. The invitation contained a link, and people agreeing to participate in the survey clicked on the link and were redirected to a webpage with the questionnaire. This helped guarantee respondent anonymity and meant we could reach a more geographically diverse population.

\section{Survey development}

The design of the questionnaire used in the online survey was initially based on previous literature on PPSDM. Already-existing measures were used: Chen et al. (2011) for measuring healthcare professionals' provision of information; Lee and Lin (2009) and Warren-Findlow et al. (2012) for self-efficacy; Fassaert et al. (2007) and Chen et al. (2011) for attentive listening; Briggs et al. (2011) and Camacho (2011) for proactive behaviour; and Kriston et al. (2010), Camacho (2011) and Chen et al. (2011) for PPSDM.

A preliminary version of the survey was pretested. To assure the content validity of the measures all items were discussed both with health care professionals specialized in haemophilia treatment and with researchers on the healthcare field. They were asked for their opinion on each item, to determine whether to retain it, to remove it or to make changes in the wording.

Finally, to assess the content validity of the measures, we pre-tested the resultant survey with a pilot sample of 
patients with haemophilia. This pre-test suggested minor changes in the wording of some questions.

\section{Measurement checks: reliability and construct validity} Following Churchill's (1979) and Gerbing and Anderson's (1988) methodological recommendations, we evaluated the psychometric properties (reliability, convergent validity and discriminant validity) of the measurement scales used. We ran a confirmatory factor analysis (CFA) using EQS 6.2.

The results of the CFA indicate that all indicators load significantly $(\mathrm{p}<0.001)$ and substantively (standardized factor loadings 0.6 or above) on their respective theoretical constructs, supporting convergent validity. Reliability is evaluated using the composite reliability (CR) and the average variance extracted (AVE). These indicators exceed the recommended threshold values of 0.6 and 0.5 respectively (Table 2). Discriminant validity was also supported as the squared correlation between each pair of factors does not exceed the AVE of each.

\section{Results}

\section{Descriptive analysis and control variables}

The measurement model was found to be satisfactory, so we then estimated the descriptive data and correlations between the different dimensions (factors). As is shown in Table 3, correlation analysis indicates that all the dimensions are positively and significatively correlated. Before evaluating the results of the structural equation model, we checked whether the dimensions differed in terms of the variables age and health literacy. ${ }^{1}$ Gender differences were not considered as only males are affected by haemophilia. As significant differences were not founded, the structural equation model was performed without including age or health literacy as control variables.

\section{Proposed model}

Regarding the results of the causal model, as Table 4 shows, the goodness-of-fit indices are satisfactory and four of the five proposed hypotheses are supported. According to these results, provision of information has a positive effect on self-efficacy $\left(\mathrm{H} 1: \gamma_{1}=0.230\right)$; attentive listening affects proactive behaviour $\left(\mathrm{H} 2: \gamma_{2}=0.318\right)$; self-efficacy also has a positive effect on proactive behaviour $\left(\mathrm{H} 3: \beta_{3}=0.338\right)$; and proactive behaviour has a positive effect on PPSDM (H5: $\left.\beta_{5}=0.453\right)$. All the relationships considered were significative, except the one between self-efficacy and PPSDM (H4). The results cannot support this hypothesis.

\footnotetext{
${ }^{1}$ The authors would like to thank a reviewer for suggesting the possible importance of this control variable. In this work we measured health literacy by three different indices. The results were the same in the three cases.
}

Nevertheless, as it is shown in Table 5, although selfefficacy does not have a direct effect on PPSDM (H4 rejected), an indirect effect is evident, resulting from the mediating role of proactive behaviour. These results show that provision of information and attentive listening influence PPSDM trough two intervening variables (also called mediators): self-efficacy and proactivity behaviour. $^{2}$

\section{Discussion}

SDM is particularly important to research in health care and especially in chronic illness where the patients need knowledge and skills all along their lives. Following the literature about the patient perspective of SDM our research proposes a model in which the variables provision of information and attentive listening have an effect over PPSDM through two intervening variables (selfefficacy and proactivity). To the best of our knowledge no previous research have analyzed the relationship between provision of information and attentive listening on PPSDM. Patient participation on SDM depends on the communication style of the doctors (Chhabra et al. 2013) and also on patients' preferences (Petriwskyj et al. 2014; Flynn et al. 2006). For this reason, we propose that provision of information and attentive listening do not drive directly SDM but through self-efficacy and proactivity.

Previous research have found that the more proactive is the patient the higher is his/her satisfaction with the health care system (Fullerton and McCullough 2014) and the bigger is his/her adherence to preventive health care (Kahana et al. 2010). This work shows that proactivity is a key aspect of PPSDM for patients with chronic illnesses. This is because asking for information reflects the patient's perception that the healthcare professional is listening attentively. Besides, the doctor can see this proactive behaviour as a sign that the patient wants to participate in the decision-making. Our results suggest that the fact that the patient searches for and requests information (i.e. in the form of formulating questions or manifesting disagreement) is fundamental for them to feel they are participating in the decision-making.

Our study raises the question: why, contrary to expectations, does self-efficacy not have a direct effect on PPSDM? A possible explanation might be that selfefficacy could generate in the patient an exaggerated feeling of his or her own ability. The patients may feel independent enough to take the decision themselves, so

\footnotetext{
${ }^{2}$ Recent statistical techniques of mediation analysis can be seen in Hayes (2009). The effect of a variable X over Y may come to be through a variety of forces both direct and indirect (this effect appears when $\mathrm{X}$ significative influences $M$ and $M$, at the same time, significative influences $Y$ ). In this work, the EQS command Effect Decomposition was used to analyze the indirect effects. Variable $\mathrm{M}$ is an intervening or mediator variable.
} 
Table 2 Measurement model: reliability and validity $(\mathrm{N}=181)$

\begin{tabular}{|c|c|c|c|c|c|}
\hline $\begin{array}{l}\text { Factor }(F) \\
\text { variables }\end{array}$ & $\begin{array}{l}\text { Standardised factor } \\
\text { loading }\end{array}$ & t Student & $\begin{array}{l}\text { Composite Reliability } \\
\text { (CR) }\end{array}$ & $\begin{array}{l}\text { Average Variance Extracted } \\
\text { (AVE) }\end{array}$ & Correlations \\
\hline Provision of information (F1: PI) & & & 0.930 & 0.770 & $\mathrm{Fl}-\mathrm{F} 2: 0.759$ \\
\hline PI1 & 0.821 & 10.139 & & & $\mathrm{Fl}-\mathrm{F} 3: 0.221$ \\
\hline $\mathrm{Pl} 2$ & 0.938 & 13.491 & & & $\mathrm{Fl}-\mathrm{F} 4: 0.230$ \\
\hline $\mathrm{Pl} 3$ & 0.862 & 12.438 & & & F1-F5: 0.622 \\
\hline PI4 & 0.884 & 13.910 & & & F2-F3: 0.193 \\
\hline Attentive listening (F2: AL) & & & 0.938 & 0.833 & $F 2-F 4: 0.311$ \\
\hline AL1 & 0.887 & 12.650 & & & F2-F5: 0.655 \\
\hline AL2 & 0.942 & 16.611 & & & F3-F4: 0.406 \\
\hline AL3 & 0.909 & 12.388 & & & $\begin{array}{l}\text { F3-F5: } 0.312 \\
\text { F4-F5: } 0.450\end{array}$ \\
\hline Self-efficacy (F3: SE) & & & 0.901 & 0.754 & \\
\hline SE1 & 0.769 & 10.757 & & & \\
\hline SE2 & 0.942 & 12.643 & & & \\
\hline SE3 & 0.885 & 12.133 & & & \\
\hline Proactive behaviour (F4: PB) & & & 0.815 & 0.595 & \\
\hline PB1 & 0.756 & 8.846 & & & \\
\hline PB2 & 0.820 & 10.871 & & & \\
\hline PB3 & 0.736 & 9.810 & & & \\
\hline PPSDM (F5) & & & 0.934 & 0.740 & \\
\hline PPSDM1 & 0.890 & 13.056 & & & \\
\hline PPSDM2 & 0.844 & 10.993 & & & \\
\hline PPSDM3 & 0.856 & 12.219 & & & \\
\hline PPSDM4 & 0.861 & 14.635 & & & \\
\hline PPSDM5 & 0.849 & 13.663 & & & \\
\hline
\end{tabular}

Table 3 Means, standard deviations and correlations for all scales $(\mathbf{N}=181)$

\begin{tabular}{|c|c|c|c|c|c|c|c|}
\hline Dimensions & Mean (SD) & & PI & $A L$ & SE & PB & $\overline{\text { PPSDM }}$ \\
\hline $\mathrm{PI}$ & 4.05 & $(0.80)$ & 1 & & & & \\
\hline $\mathrm{AL}$ & 4.06 & $(0.78)$ & $0.720^{* *}$ & 1 & & & \\
\hline SE & 4.17 & $(0.70)$ & $0.193^{* *}$ & $0.167^{*}$ & 1 & & \\
\hline PB & 3.99 & $(0.77)$ & $0.222^{* *}$ & $0.284^{* *}$ & $0.366^{* *}$ & 1 & \\
\hline PPSDM & 3.79 & $(0.81)$ & $0.592^{* *}$ & $0.618^{* *}$ & $0.294^{* *}$ & $0.408^{* *}$ & 1 \\
\hline
\end{tabular}

${ }^{*} \mathrm{p}<0.05 ;{ }^{* *} \mathrm{p}<0.001$

Table 4 Results of structural equation model analyses $(\mathbf{N}=181)$

\begin{tabular}{ll}
\hline Causal relations & Standardised factor loadings (t Student) \\
\hline H1 (+): Provision of information $(P I) \rightarrow$ self-efficacy (SE) & $0.230(2.569)$ \\
H2 (+): Attentive listening (AL) $\rightarrow$ proactive behaviour (PB) & $0.318(2.909)$ \\
H3 (+): Self-efficacy $(S E) \rightarrow$ proactive behaviour (PB) & $0.338(3.613)$ \\
H4 (+): Self-efficacy (SE) $\rightarrow$ PPSDM & $0.135(1.530)$ \\
H5 (+): Proactive behaviour $(P B) \rightarrow$ PPSDM & $0.453(4.966)$
\end{tabular}

$\mathrm{X}^{2} \mathrm{~S}-\mathrm{B}(129)=257.9029(\mathrm{p}=0.00000), \mathrm{BBNNFI}=0.909, \mathrm{CFI}=0.923, \mathrm{GFI}=0.840, \mathrm{RMSEA}=0.075$

$S^{* *}$ supported at $95 \%$ level, NS not supported 
Table 5 Total and indirect effects $(\mathrm{N}=181)$

\begin{tabular}{ll}
\hline & $\begin{array}{l}\text { Standardised } \\
\text { coefficients } \\
\text { (t Student) }\end{array}$ \\
\hline $\begin{array}{l}\text { Total effect } \\
\text { Provision of information (PI) } \rightarrow \text { self-efficacy (SE) }\end{array}$ & $0.230(2.569)$ \\
Provision of information (PI) $\rightarrow$ proactive behaviour & $0.078(2.189)$ \\
$\quad$ PB) & $0.066(2.638)$ \\
Provision of information (PI) $\rightarrow$ PPSDM & $0.318(2.909)$ \\
Attentive listening (AL) $\rightarrow$ proactive behaviour (PB) & $0.144(2.682)$ \\
Attentive listening (AL) $\rightarrow$ PPSDM & $0.338(3.613)$ \\
Self-efficacy (SE) $\rightarrow$ proactive behaviour (PB) & $0.288(3.699)$ \\
Self-efficacy (SE) $\rightarrow$ PPSDM & $0.453(4.966)$ \\
Proactive behaviour (PB) $\rightarrow$ PPSDM & \\
Specific indirect effect & $0.153(3.079)$ \\
Self-efficacy (SE) $\rightarrow$ PPSDM via proactive behaviour & \\
\hline
\end{tabular}

they do not perceive the decision to be shared. However, the results obtained show that self-efficacy has an indirect and significative effect on PPSDM through proactive behaviour. Thus, self-efficacy is also a crucial factor when trying to elicit in the patient the feeling that he/she is participating in the decision-making.

These results are coherent with the studies that propose to develop communication training programs dealing with all relevant functions of communication between physicians and patients, such as SDM (de Haes and Bensing 2009; Levinson et al. 2010; Bensing et al. 2013). Thus, our work contributes to extend the idea that is essential for the doctor to establish a collaborative dialogue to encourage patient self-efficacy and proactivity in requesting information. Provision of information and attentive listening can help the patients to value their personal knowledge and expertise in relation to their doctors. These strategies are very necessary as it is widely known that "patients also place much emphasis on the medical information provided, but do not recognize, or undervalue, the complementary expertise that they can bring to the SDM encounter" (Joseph-Williams et al. 2014, p. 307).

The exchange of information in the patient-physician communication is related to characteristics of patients, characteristics of doctors and to the clinical situation (Waitzkin 1984). The same can be said with regards to SDM. Thus, it would be interesting to compare the model proposed in this work with other types of patients and to consider control variables that could be related with SDM. Among those potential control variables it should be taken into account personal characteristics (such as gender, health literacy, severity of the illness and self-advocacy) or institutional characteristics (i.e. type of institution or degree of use of communication tools such as social media or mobile apps). Moreover, it could be particularly interesting analyze the importance of empowering experience as a control variable (Suárez et al. 2016).

This research has some limitations that could be addressed in future studies. First, the cross-sectional design, that is, the data came from a specific point of time, what can affect the causality. Thus, this research could be used as a reference in future studies dealing with longitudinal data. Second, as haemophilia affects only males, the results suffer from gender bias. Future research should take into account whether there could be differences between genders in the case of other chronic illness. Finally, using an online survey is inherently problematical, in particular it is difficult to locate a representative sample (Baker et al. 2010).

\section{Conclusions}

SDM is regarded as one of the "younger" functions in medical communication research and "patient-based studies are still in their infancy" (Bensing et al. 2013, p. 288). Recent studies call for an analysis of the antecedents of patient perceptions of SDM on PPSDM (Shay and Lafata 2015; Joseph-Williams et al. 2014). The results presented here help to bridge this gap by focusing specifically on the patient's perspective of SDM. The proposed hypotheses are tested through SEM which is quite novel and shows high potential in the SDM domain. It should be taken into account that in this field of research it is very interesting to examine the relationship between different variables that represent patient' self-perceptions. With this sort of variables, which should be measured as latent variables, that is, through multiple indicators, is particularly useful to apply SEM.

Our study supports previous research related with the necessity of taking into account provision of information and attentive listening as core competencies in medical education (Hartman et al. 2013; Mazzi et al. 2013). Departing from this previous studies, our research shows that provision of information and attentive listening increase PPSDM via their respective positive effects on patient self-efficacy and patient proactive behaviour in requesting information.

We would strongly recommend incorporating communication training into medical education with the aim of raising PPSDM. These training programs should focus on encouraging healthcare professionals' attentive listening and provision of information and, at the same time, they should also consider patient self-efficacy and proactivity in requesting information. 
Thus healthcare professionals can improve PPSDM by providing correct information that is personalized according to the patient's individual circumstances. Other important skills for healthcare professionals are giving clear explanations and checking the patient's understanding. Healthcare professionals should also create an environment of attentive listening. In other words, they should encourage patients to discuss without interruption or premature closure their main concerns, making them feel comfortable and making it easy to elicit their perceptions about their illness and associated feelings. Provision of information and attentive listening may be fundamental in helping patients not to undervalue their personal knowledge and expertise in relation to the doctor so they adopt a more active position in requesting information and in their relationship with their doctor.

It should also be highlighted that, in the sample analyzed, it has not be possible to test the direct effect of selfefficacy over PPSDM. This result suggests that patients can overvalue, or undervalue, his or her own ability. Doctors and society in general need to assimilate patient' proactive behaviour with the idea that the patient is acting as the doctor's partner. We believe that the patient assumes this type of behaviour when they realize that their input in the interaction with their doctor is highly valuable.

Thus interventions to raise PPSDM should not be directed solely at the healthcare professional, but should also include the patient and the people close to the patient. Specifically, another line of action is to support patients and/or the people close to them so that they are capable of taking the initiative to debate with their doctor, search for and ask for information and openly express their opinion, even their disagreement. The aim is to encourage behaviour that is responsible and proactive, respectful and directed at becoming conscious of the need to participate and feel that they are participating in the decision-making. The new information and communications technologies offer quick, convenient tools (such as blogs, social networks, and mobile phone apps) to encourage this proactive behaviour and evaluate the changes occurring in the patient's proactive behaviour and self-efficacy.

\footnotetext{
Abbreviations

AL: attentive listening; AVE: average variance extracted; CFA: confirmatory factor analysis; CR: composite reliability; PB: proactive behaviour; Pl: information provision; PPSDM: patients' perception of shared decision-making; SD: standard deviation; SDM: shared decision-making; SE: self-efficacy; SEM: structural equation modelling; WHO: World Health Organization.

\section{Authors' contributions}

$A B R, L S, A S$ and RV have contributed to the study concept and method design. All authors have made substantial contributions to analysis and interpretation of data. All authors have been involved in drafting or revising the manuscript critically for important intellectual content, and final approval of the version to be published. All authors read and approved the final manuscript.
}

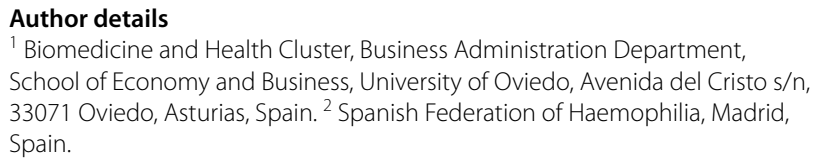

\section{Acknowledgements}

The authors wish to thank Spanish Federation of Haemophilia and Spanish Society of Haemostasis and Thrombosis for their collaboration in the collection of data, and the student Lucía Huergo for their participation in the creation of online web forms. The authors would also like to thank the reviewers for their helpful comments throughout the review process.

\section{Competing interests}

The authors declare that they have no competing interests.

\section{Funding}

This work was funded by the Spanish Ministry of Science and Innovation under the 2011-2015 Call for R\&D projects (ECO2012-31300). This paper was finished during the third author's stay as visiting scholar at the Marketing Department of the University of Maryland. Financial support from the Cátedra Extraordinaria Fundación Ramón Areces de Distribución Comercial is gratefully acknowledged. The sponsors were not involved in the writing of the report or in the decision to submit the paper for publication. Design of the survey and control of the research data rested with the University of Oviedo investigator team.

Received: 26 September 2015 Accepted: 16 August 2016

Published online: 22 August 2016

\section{References}

Athale A, Giguere A, Barbara A, Krassova S, lorio A (2014) Developing a twosided intervention to facilitate shared decision-making in haemophilia: decision boxes for clinicians and patient decision aids for patients. Haemophilia 20:800-806. doi:10.1111/hae.12495

Baker R, Blumberg SJ, Brick JM, Couper MP, Courtright M, Dennis JM, Zahs D (2010) Research synthesis: AAPOR report on online panels. Public Opin Quart 74:711-781.doi:10.1093/poq/nfq048

Bandura A (1998) Health promotion from the perspective of social cognitive theory. Psychol Health 13:623-649. doi:10.1080/08870449808407422

Bensing J, Rimondini M, Visser A (2013) What patients want. Patient Educ Couns 90:287-290. doi:10.1016/j.pec.2013.01.005

Blair L, Légaré $F(2015)$ Is shared decision making a utopian dream or an achievable goal? Patient 8:471-476. doi:10.1007/s40271-015-0117-0

Branda ME, LeBlanc A, Shah ND, Tiedje K, Ruud K, van Houten H, Montori VM (2013) Shared decision making for patients with type 2 diabetes: a randomized trial in primary care. BMC Health Serv Res. doi:10.1186/1472-6963-13-301

Briggs AM, Jordan JE, O'Sullivan PB, Buchbinder R, Burnett AF, Osborne RH, Straker LM (2011) Individuals with chronic low back pain have greater difficulty in engaging in positive lifestyle behaviours than those without back pain: an assessment of health literacy. BMC Musculoskelet Disord 12:161-171. doi:10.1186/1471-2474-12-161

Burton D, Blundell N, Jones M, Fraser A, Elwyn G (2010) Shared decision-making in cardiology: do patients want it and do doctors provide it? Patient Educ Couns 80:173-179. doi:10.1016/j.pec.2009.10.013

Camacho N (2011) Health and marketing: essays on physician and patient decision-making. Dissertation, Erasmus Research Institute of Management

Carpenter DM, DeVellis RF, Fisher EB, DeVellis BM, Hogan SL, Jordan JM (2010) The effect of conflicting medication information and physician support on medication adherence for chronically ill patients. Patient Educ Couns 81:169-176. doi:10.1016/j.pec.2009.11.006

Charles C, Gafni A, Whelan T (1997) Shared decision-making in the medical encounter: what does it mean? (or it takes at least two to tango). Soc Sci Med 44:681-692. doi:10.1016/S0277-9536(96)00221-3

Chen MF, Wang RH, Cheng CP, Chin CC, Stocker J, Tang SM, Chen SW (2011) Diabetes empowerment process scale: development and psychometric testing of the Chinese version. J Adv Nurs 67:204-214. doi:10.1111/j.1365-2648.2010.05486.x 
Chhabra KR, Pollak KI, Lee SJ, Back AL, Goldman RE, Tulsky JA (2013) Physician communication styles in initial consultations for hematological cancer. Patient Educ Couns 93:573-578. doi:10.1016/j.pec.2013.08.023

Churchill G (1979) A paradigm for developing better measures of marketing constructs. J Mark Res 16:64-73. doi:10.2307/3150876

Cramm JM, Nieboer AP (2014) The importance of productive patient-professional interaction for the well-being of chronically ill patients. Qual Life Res 24:1-7

de Haes H, Bensing J (2009) Endpoints in medical communication research, proposing a framework of functions and outcomes. Patient Educ Couns 74:287-294. doi:10.1016/.jpec.2008.12.006

Elwyn G, Frosch D, Thomson R, Joseph-Williams N, Lloyd A, Kinnersley P, Barry M (2012) Shared decision making: a model for clinical practice. J Gen Intern Med 27:1361-1367. doi:10.1007/s11606-012-2077-6

Entwistle VA, Watt IS (2006) Patient involvement in treatment decision-making: the case for a broader conceptual framework. Patient Educ Couns 63:268-278. doi:10.1016/j.pec.2006.05.002

Fassaert T, van Dulmen S, Schellevis F, Bensing J (2007) Active listening in medical consultations: development of the Active Listening Observation Scale (ALOS-global). Patient Educ Couns 68:258-264. doi:10.1016/j. pec.2007.06.011

Fiks AG, Hughes CC, Gafen A, Guevara JP, Barg FK (2011) Contrasting parents' and pediatricians' perspectives on shared decision-making in ADHD. Pediatrics 127:188-196. doi:10.1542/peds.2010-1510

Flynn KE, Smith MA, Vanness D (2006) A typology of preferences for participation in health care decision making. Soc Sci Med 63:1158-1169. doi:10.1016/j.socscimed.2006.03.030

Frosch DL, Elwyn G (2014) Don't blame patients, engage them: transforming health systems to address health literacy. J Health Commun 19:10-14. doi :10.1080/10810730.2014.950548

Fullerton S, McCullough T (2014) Patient proactivity: behaviors, attitudes, and its relationship with satisfaction with the American Health Care Delivery System. Health Mark Q 31:78-96. doi:10.1080/07359683.201 4.874879

Gerbing DW, Anderson JC (1988) An updated paradigm for scale development incorporating unidimensionality and its assessment. J Mark Res 25:186-192. doi:10.2307/3172650

Hamann J, Neuner B, Kasper J, Vodermaier A, Loh A, Deinzer A, Härter M (2007) Participation preferences of patients with acute and chronic conditions. Health Expect 10:358-363. doi:10.1111/j.1369-7625.2007.00458.x

Hartman TC, van Rijswijk E, van Dulmen S, van Weel-Baumgarten E, Lucassen PL, van Weel C (2013) How patients and family physicians communicate about persistent medically unexplained symptoms. A qualitative study of video-recorded consultations. Patient Educ Couns 90:354-360. doi:10.1016/j.pec.2011.02.014

Hausman A (2004) Modeling the patient-physician service encounter: improving patient outcomes. J Acad Mark Sci 32:403-417. doi:10.1177/0092070304265627

Hayes AF (2009) Beyond Baron and Kenny: statistical mediation analysis in the new millennium. Commun Monogr 76:408-420. doi:10.1080/03637750903310360

Heckman JE, Chamie K, Maliski SL, Fink A, Kwan L, Connor SE, Litwin MS (2011) The role of self-efficacy in quality of life for disadvantaged men with prostate cancer. J Urol 186:1855-1861. doi:10.1016/j.juro.2011.06.059

Hölzel LP, Kriston L, Härter M (2013) Patient preference for involvement experienced involvement, decisional conflict, and satisfaction with physician: a structural equation model test. BMC Health Serv Res 13:231-241. doi:10.1186/1472-6963-13-231

Jagosh J, Boudreau JD, Steinert Y, MacDonald ME, Ingram L (2011) The importance of physician listening from the patients' perspective: enhancing diagnosis, healing, and the doctor-patient relationship. Patient Educ Couns 85:369-374. doi:10.1016/j.pec.2011.01.028

Janz N, Wren P, Copeland L, Lowery J, Goldfarb S, Wilkins E (2004) Patient-physician concordance: preferences, perceptions, and factors influencing the breast cancer surgical decision. J Clin Oncol 22:3091-3098. doi:10.1200/ JCO.2004.09.069

Joosten EA, DeFuentes-Merillas L, De Weert GH, Sensky T, Van Der Staak CP, De Jong CA (2008) Systematic review of the effects of shared decisionmaking on patient satisfaction, treatment adherence and health status. Psychother Psychosom 77:219-226. doi:10.1159/000126073
Joseph-Williams N, Elwyn G, Edwards A (2014) Knowledge is not power for patients: a systematic review and thematic synthesis of patient-reported barriers and facilitators to shared decision making. Patient Educ Couns 94:291-309. doi:10.1016/j.pec.2013.10.031

Kahana E, Kahana B (2001) On being a proactive health care consumer: making an "unresponsive" system work for you. Res Sociol Health Care 19:21-44. doi:10.1016/S0275-4959(01)80005-3

Kahana E, Kahana B (2003) Patient proactivity enhancing doctor-patient-family communication in cancer prevention and care among the aged. Patient Educ Couns 50:67-73. doi:10.1016/50738-3991(03)00083-1

Kahana E, Cheruvu VK, Kahana B, Kelley-Moore J, Sterns S, Brown JA, Stange KC (2010) Patient advocacy and cancer screening in late life. Open Longev Sci 4:20-29

King CP (1978) Keep your communication climate healthy. Pers J 57:204-206

Kriston L, Scholl I, Hölzel L, Simon D, Loh A, Härter M (2010) The 9-item Shared Decision Making Questionnaire (SDM-Q-9). Development and psychometric properties in a primary care sample. Patient Educ Couns 80:94-99. doi:10.1016/j.pec.2009.09.034

Lam WW, Kwok M, Chan M, Hung WK, Ying M, Or A, Fielding R (2014) Does the use of shared decision-making consultation behaviors increase treatment decision-making satisfaction among Chinese women facing decision for breast cancer surgery? Patient Educ Couns 94:243-249. doi:10.1016/j. pec.2013.11.006

Lee YY, Lin JL (2009) The effects of trust in physician on self-efficacy, adherence and diabetes outcomes. Soc Sci Med 68:1060-1068. doi:10.1016/j. socscimed.2008.12.033

Légaré F, O'Connor AM, Graham ID, Saucier D, Côté L, Blais J, Cauchon M, Paré L (2006) Primary health care professionals'views on barriers and facilitators to the implementation of the Ottawa Decision Support Framework in practice. Patient Educ Couns 63:380-390. doi:10.1016/j.pec.2006.04.011

Levinson W, Lesser CS, Epstein RM (2010) Developing physician communication skills for patient-centered care. Health Aff 29:1310-1318. doi:10.1377/ hlthaff.2009.0450

Liang W, Burnett CB, Rowland JH, Meropol NJ, Eggert L, Hwang YT (2002) Communication between physicians and older women with localized breast cancer: implications for treatment and patient satisfaction. J Clin Oncol 20:1008-1016. doi:10.1200/JCO.20.4.1008

Mallin ML, Ragland CB, Finkle TA (2014) The proactive behavior of younger salespeople: antecedents and outcomes. J Mark Channels 21:268-278. doi:10.1080/1046669X.2014.945359

Maly RC, Umezawa Y, Leake B, Silliman RA (2004) Determinants of participation in treatment decision-making by older breast cancer patients. Breast Cancer Res Treat 85:201-209. doi:10.1023/B:BREA.0000025408.46234.66

Manco-Johnson MJ, Abshire TC, Shapiro AD, Riske B, Hacker MR, Kilcoyne R, Evatt BL (2007) Prophylaxis versus episodic treatment to prevent joint disease in boys with severe hemophilia. New Engl J Med 357:535-544. doi:10.1056/NEJMoa067659

Mazzi MA, Bensing J, Rimondini M, Fletcher I, Van Vliet L, Zimmermann C (2013) How do lay people assess the quality of physicians' communicative responses to patients' emotional cues and concerns? An international multicentre study based on videotaped medical consultations. Patient Educ Couns 90:347-353. doi:10.1016/j.pec.2011.06.010

McAdam MC (2013) Economic implications of type 2 diabetes management. Am J Manag Care 19:143-148

Oftedal B, Karlsen B, Bru E (2010) Perceived support from healthcare practitioners among adults with type 2 diabetes. J Adv Nurs 66:1500-1509. doi:10.1111/j.1365-2648.2010.05329.x

Petriwskyj A, Gibson A, Webby G (2014) Participation and power in care: exploring the "client" in client engagement. J Aging Stud 31:119-131. doi:10.1016/j.jaging.2014.09.007

Salem K, Eshghi P (2013) Dental health and oral health-related quality of life in children with congenital bleeding disorders. Haemophilia 19:65-70. doi:10.1111/hae.12002

Shay LA, Lafata JE (2015) Where is the evidence? A systematic review of shared decision making and patient outcomes. Med Decis Mak 35:114-131. doi: 10.1177/0272989X14551638

Siegel CA, Lofland JH, Naim A, Gollins J, Walls DM, Rudder LE, Reynolds C (2015) Novel statistical approach to determine inflammatory bowel disease: patients' perspectives on shared decision making. Patient. doi:10.1007/s40271-015-0126-z 
Suárez A, del Río AB, Suárez L, Vázquez R (2016) Empower me? Yes, please, but in my way: different patterns of experiencing empowerment in patients with chronic conditions. Health Commun. doi:10.1080/10410236.2016.1 196409

Tariman JD, Berry DL, Cochrane B, Doorenbos A, Schepp K (2010) Preferred and actual participation roles during health care decision making in persons with cancer: a systematic review. Ann Oncol 21:1145-1151. doi:10.1093/ annonc/mdp534

Tates K, Meeuwesen L (2001) Doctor-parent-child communication. A (re) view of the literature. Soc Sci Med 52:839-851. doi:10.1016/ S0277-9536(00)00193-3

van den Brink-Muinen A, Spreeuwenberg P, Rijken M (2011) Preferences and experiences of chronically ill and disabled patients regarding shared decision-making: does the type of care to be decided upon matter? Patient Educ Couns 84:111-117. doi:10.1016/j.pec.2010.07.032
Waitzkin H (1984) Doctor-patient communication: clinical implications of social scientific research. JAMA 252:2441-2446. doi:10.1001/ jama.1984.03350170043017

Warren-Findlow J, Seymour RB, Huber LRB (2012) The association between self-efficacy and hypertension self-care activities among African American adults. J Commun Health 37:15-24. doi:10.1007/s10900-011-9410-6

World Health Organization Global (2011) Status report on noncommunicable diseases. World Health Organization, Geneva

Wunderlich T, Cooper G, Divine G, Flocke S, Oja-Tebbe N, Stange K, Lafata JE (2010) Inconsistencies in patient perceptions and observer ratings of shared decision making: the case of colorectal cancer screening. Patient Educ Couns 80:358-363. doi:10.1016/j.pec.2010.06.034

\section{Submit your manuscript to a SpringerOpen ${ }^{\circ}$ journal and benefit from:}

Convenient online submission

- Rigorous peer review

- Immediate publication on acceptance

- Open access: articles freely available online

- High visibility within the field

- Retaining the copyright to your article

Submit your next manuscript at $\$$ springeropen.com 